\title{
A Model to Predict the Performance of Drilling Operation Using SVM Approach in One of the Iranian Oilfields
}

\author{
Masoud Kakoli $^{1}$, Arash Ebrahimabadi ${ }^{2}$, Behnam Mirshekari ${ }^{1}$, Jamal Sheikhzakariaee ${ }^{1}$ \\ ${ }^{I}$ Department of Petroleum Engineering, Science and Research Branch, Islamic Azad University, Tehran, Iran. \\ ${ }^{2}$ Department of Mining, Qaemshahr Branch, Islamic Azad University, Qaemshahr, Iran.
}

*Corresponding Author: Arash Ebrahimabadi, Department of Mining, Qaemshahr Branch, Islamic Azad University, Qaemshahr, Iran.

\begin{abstract}
Drilling operations in the oil and gas industry have a special place, and it is one of the leading and costly parts of this industry. No doubt there are many factors in the performance of drilling operations, including technical and economic factors. In this research, we will try to examine the critical parameters in the operation of drilling mast. The higher the rate of penetration, the faster the drilling speed and thus it reduces the time and will ultimately decrease the cost of the entire operation. Therefore, to gain the optimal drilling performance, there should be an assessment and proper prediction of the rate of drill penetration rate. Since the quality and properties of the formations and the depth of reservoir's layer are one of the most influential factors in the penetration rate of rock. Based on the results of the model, CSA LSSVM made in this study, the correlation coefficient the of total drill penetration rate recorded in the drilling reports and predicted value was 0.989, and the absolute error of the mean is also as low as $8.39 \%$.
\end{abstract}

Keywords: Drilling Performance, Support Vector Machine (SVM), Penetration Rate

\section{INTRODUCTION}

Due to the problems in the automatic process of maintaining the proper lithology and maintaining well conditions parameters for drilling, the drilling industry needs a new method that the workers would observe the desired information at the desired time and control the drilling parameters. Thus, by analyzing field data, using the predictive model, and subsequently evaluating and correcting the useful parameters, a dramatic increase in the efficiency of the drilling operations and, reduction of costs can be achieved [1-7].The higher the penetration rate, the higher the speed of drilling a well, resulting in a time reduction, which ultimately leads to a reduction in the total cost of the operation. Therefore, to become the optimal drilling operation, there should be an assessment and proper prediction of drill penetration rate. Thus, the structural properties and reservoir depth are the most influential factors in the rate of rock penetration; in respect of the way, as the depth increases, the formations become harder and the penetration rate decreases. Moreover, due to the depth of the wells in the oil fields of Iran, the assessment of the penetration rate is of importance [8-15].

\subsection{Support Vector Machine (SVM)}

Support vector machine is one of the supervisory learning methods that can be used for categorization and regression. A Support vector machine is mostly a two-class categorization that separates classes by a linear boundary. In this approach, the closest examples are called vector by vectors to the decision boundary. These vectors determine the boundary of decision-making equation. This method is due to the use of the structural risk minimization principle, which is applied by maximizing the distance between two superconducting transcoders from the support vectors of both classes. Contrary to the empirical risk minimization mode that attempts to minimize the training error, the performance is better on data which model is not made with them; For simplicity in understanding, the purpose of expressing the theory of a support vector machine, the most straightforward possible model for the two-class separation in a separable state begins linearly.In this method, it is assumed that the samples

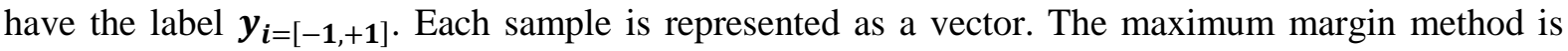
used to find the optimal decision boundary. Therefore, the decision boundary, in addition to having to split all instances of both classes correctly into two categories, must also find the boundary of 
decision, which has the greatest distance from all backward vectors. The mathematical expression of the decision boundary in vector space can be as follows [16-23].

$f(x)=\operatorname{sgn}(w \cdot x+b)$

Where $\mathrm{w}$ is the normal vector of the hyperplane and $\mathrm{b}$ is the width from its origin. As stated, the decision boundary should correctly classify the samples, whose mathematical expression is as follows.

$$
y_{i}(w \cdot x+b) \geq 1
$$

Considering the importance of the accuracy of the predictive models in this research, we will try to use new methods of modeling that will yield more accurate and reliable results, which will be used by the SVM technique [24-33]. It is worth noting that until now, comprehensive research on the use of this method for predicting drilling performance has not been reported. Regardless of the type of drilling rigs used in Iran and according to the data obtained from previous drilling operations, the objective of this paper is to provide a model for predicting the penetration rate. By comparing and studying the useful factors about the mud, the type of drilling, hydraulics, the rig power and, the study of the conditions can be achieved using modern modeling techniques [34-45].

\section{Proposed Comprehensive Model}

In this section, after defining common symbols, the limitations and functions of the model, we will model the comprehensive classification model geometrically and also in the form of mathematical programming. The Comprehensive Classification Model is designed to incorporate both SVM's advanced and improved models, as well as the linear and non-linear multi-objective, mathematical programming models that have been presented so far, as well as the creation of new particular situations. In real-time modeling, the Support vector machine is used,andthe recorded drilling rig, as well as graphing operations, are used to predict the penetration rate. But for data to be applicable, some changes and corrections are required on the data [46-51]. In this chapter, we first discuss this issue and examine the data used, and then, the modeling is performed to achieve the desired goal,and the results are presented to express the status of the model. After the creation of the model, its weaknesses and strengths have been examined.In general, the factors affecting drilling speed can be divided into three main parts:

- Drill specifications and working conditions.

- Characteristics of the formation

- Characteristics of Drilling and Hydraulic Well Drilling

The bit specifications and operating conditions include bit type, hydraulic bit power, bit weight and bit speed. Also, the weightof the drill and the rotational speed is used as the input section. Naturally, to obtain a complete model, it is necessary to influence the factors and their individual effects on the formation. Factors affecting the impact of the formationof the penetration rate include porosity, formation pressure, hardening of the formation, tensile and compressive strength. Due to the available and available data in superior databases, there was not enough data to influence the above factors. But during discussions with expert's guides, the best way to affect the parameters was to change the size of the formation. These changes are noticeable in places where lithology improves $100 \%$. But low torque variations can be attributed to low lithological mutations, in other words, close difficulty, and equal pressures [52-58]. As a result, the influence of the torque cannotbe ignored on the penetration rate. This theory may later be taken into account by increasing the accuracy of the devices, and thus a better and more accurate correlation can be found for the rate of drilling permeation. To achieve the desired results, torque should be considered as one of the input parameters. The properties of drilling mud that are known to be efficient at drilling speed include plastic viscosity, bentonite content in mud, number of drilling bits and fluid viscosity.However, due to the available and independent parameters in the input section, the drilling mud weight is used.

Required information for modeling is provided in collaboration with a group of engineers in Iranian oil companies. The related information of Iran's oil field in Khangiran includes daily bit drilling data and some geological reports. In the data selection section, all data that affects the drilling speed has 
A Model to Predict the Performance of Drilling Operation Using SVM Approach in One of the Iranian Oilfields

been tried in various sections such as formation, drilling fluid and working conditions, to provide a comprehensive model. Due to the large volume of data, in this research, we tried to select parameters that have a significant impact on the rate of drilling permeation. With regard to the investigations concerning the drilling performance in the backup machine and the work done to improve the model in the past, it was concluded that the parameters entered the machine purely regardless of their effect on other parameters, this is a sign of weakness in their input parameters. Naturally, when the input parameters are not entered with the correct understanding, the accuracy of the answers cannot be guaranteed. For this purpose, the following parameters are selected in terms of the conditions stated as input parameters to the machine, namely the independent parameters, which is the number of about 400 data used in the machine.

Furthermore, the input and output parameters which is used in this model are statistically depicted in table 1.

Table1. The Input and Output Parameters Which Is Used in This Model

\begin{tabular}{|c|c|c|c|c|c|c|c|c|}
\hline $\begin{array}{c}\text { Depth } \\
\text { (m) }\end{array}$ & $\begin{array}{c}\text { Bit Size } \\
\text { (inch) }\end{array}$ & $\begin{array}{c}\text { Bit } \\
\text { Typ } \\
\text { e }\end{array}$ & $\begin{array}{c}\text { Weight } \\
\text { on Bit }\end{array}$ & $\begin{array}{c}\text { Bit Rotation } \\
\text { (RPM) }\end{array}$ & $\begin{array}{c}\text { Mud } \\
\text { Weight(pcf) }\end{array}$ & $\begin{array}{c}\text { Flow } \\
\text { Rate(gpm) }\end{array}$ & $\begin{array}{c}\text { Pump Pressure } \\
\text { (psia) }\end{array}$ & $\begin{array}{c}\text { Rate of Penetration } \\
\text { ROP (M/H) }\end{array}$ \\
\hline 18 & 26 & 1 & 3.5 & 35 & 65 & 100 & 0 & 0.2 \\
\hline 20 & 26 & 1 & 3.5 & 35 & 65 & 100 & 200 & 2.5 \\
\hline 1093 & $171 / 2$ & 3 & 0 & 0 & 76 & 0 & 0 & 1.63 \\
\hline 1163 & $171 / 2$ & 1 & 0 & 0 & 80 & 0 & 0 & 1.77 \\
\hline 3083 & 8.5 & 3 & 0 & 0 & 80 & 0 & 0 & 1.17 \\
\hline 2896 & 12.25 & 3 & 0 & 0 & 92 & 0 & 0 & 0.68 \\
\hline 2991 & $121 / 4$ & 3 & 0 & 0 & 101.5 & 0 & 0 & 1.42 \\
\hline 2792.6 & $121 / 4$ & 2 & 30 & 0 & 89 & 550 & 2300 & 0.21 \\
\hline 2792.6 & $121 / 4$ & 2 & 27.5 & 0 & 89 & 550 & 2320 & 0.22 \\
\hline 2796.3 & $121 / 4$ & 2 & 27.5 & 0 & 89 & 550 & 2320 & 0.2 \\
\hline 2800.25 & $121 / 4$ & 2 & 30 & 0 & 89 & 550 & 2290 & 0.17 \\
\hline 2801 & $121 / 4$ & 2 & 30 & 0 & 89 & 550 & 2300 & 0.17 \\
\hline 1900 & $121 / 4$ & 3 & 0 & 0 & 91 & 670 & 1850 & 7.02 \\
\hline 3333 & $81 / 2$ & 3 & 7.5 & 32.5 & 85.5 & 385 & 2650 & 1.56 \\
\hline 3366 & $81 / 2$ & 3 & 7.5 & 32.5 & 87 & 385 & 2650 & 1.54 \\
\hline 3387 & $81 / 2$ & 3 & 7.5 & 32.5 & 87 & 385 & 2650 & 1.54 \\
\hline 3389.5 & $81 / 2$ & 3 & 7.5 & 32.5 & 87 & 385 & 2650 & 1.54 \\
\hline 3290 & $81 / 2$ & 3 & 7.5 & 32.5 & 84 & 395 & 2650 & 1.53 \\
\hline 3570 & $61 / 8$ & 2 & 5 & 35 & 62 & 200 & 1800 & 0.69 \\
\hline 3696 & $61 / 8$ & 3 & 15 & 35 & 62 & 200 & 1700 & 0.98 \\
\hline
\end{tabular}

\section{RESULTS AND DISCUSSION}

\subsection{Investigating the Regression and Statistical Analysis in SPSS}

The factors affecting drilling speed, we deal with variables that are in some way related to several other variables. As a result, to better and more accurately answer the prediction of drilling speed, a multivariate linear regression method should be used to establish a relationship between these variables $[45,46]$. Multiple linear regression is one of the most sophisticated statistical techniques that is usually used for data whose range of measurements is a distance. Linear regression is proposed in the form of simple linear regression and multivariate linear regression. Simple linear regression predicts the value of a dependent variable based on the amount of an independent variable. However, multivariate regression is a method for the collective and individual participation of two or more independent variables in the variation of a dependent variable. Since the task is the basis of science, the prediction and the explanation of phenomena, so in researchesssthat are observing prediction and correlation, regression analysis can play a significant role. Linear regression models incorporate a broad and rich framework that meets and needs a lot of study. However, linear regression for all issues cannot be appropriate, because in some cases the response and regression variables are related to the unknown nonlinear function, but in this section, the highest correlation coefficient and the coefficient of determination according to Table 2 are related to linear regression, and other regression models are not applicable here. 
A Model to Predict the Performance of Drilling Operation Using SVM Approach in One of the Iranian Oilfields

Table2. Results of regression types

\begin{tabular}{|c|c|c|}
\hline Regression Type & Relevant factor & Determination Factor \\
\hline Non- Linear Exponential & 0.29 & 0.41 \\
\hline Non- Linear Cubic & 0.47 & 0.62 \\
\hline Non- Linear Quadratic & 0.46 & 0.61 \\
\hline Non- Linear Inverse & 0.26 & 0.53 \\
\hline Non- Linear Logarithmic & 0.30 & 0.41 \\
\hline Non- Linear Multiple linear & 0.89 & 0.94 \\
\hline
\end{tabular}

Available data were gathered to obtain regression and evaluate its performance with the help of the SPSS software. Of course, in SPSS software, according to the number of input samples, the numbers were varied, the more the number of samples was, the lower the correlation coefficient, which indicates the weakness of the software in the statistical society. The results for the sample number are shown in Table 3.

Table3. The coefficients obtained from different statistical population

\begin{tabular}{|c|c|}
\hline Sample Numbers & Relevant factor \\
\hline 300 & 0.89 \\
\hline 107 & 0.968 \\
\hline 59 & 0.99 \\
\hline
\end{tabular}

According to the table 2 and the results obtained, it shows that the higher the number of samples, the lower the correlation coefficient, and given the fact that the statistical population of the data in the oil field is high, the accuracy of using SPSS software is low. And it cannot be used as a computational reference.

\subsection{Modeling}

After the previous steps, the data is ready for modeling. At this stage, the proper equipmentis selected according to its advantages and disadvantages, and our goal is to do the job. At this stage, the model of the equipment, its structure, and its components are chosen. After selecting the equipment, the structure must be specified. The condition for the end of the training period is also determined for the car at this stage. In addition, we use support vector machines and optimization algorithms to create the appropriate model.

\subsection{Operational Criteria}

In order to evaluate the performance of the models and compare the results, criteria are needed to be used in the research. Among the standard criteria, regression coefficient, the coefficient of determination and, mean square error (MSE) were used. The value indicates the relationship between the actual data and the model, the value between negative one and one; the negative value of one represents an inverse relationship, and the relation 1describes the direct relationship,and the zero value indicates the absence of a connection between the data. The value of this variable is obtained from equation 3. The magnitude of the regression coefficient is two. If there is a substantial difference between the actual data and the model, the regression coefficient alone cannot indicate a strong relationship between the data. Therefore, another criterion that shows the difference between the actual data and the model is used. For this purpose, the MSE criterion was used. The lower this criterion, the higher the accuracy of the model. The MSE value is calculated using the relationship 3.

$$
R=\frac{\sum_{i=1}^{n}\left(x_{i}-\bar{x}\right)\left(y_{i}-\bar{y}\right)}{\sqrt{\sum_{i=1}^{n}\left(x_{i}-\bar{x}\right)^{2}} \sqrt{\sum_{i=1}^{n}\left(y_{i}-\bar{y}\right)^{2}}}
$$

In the equation $3, \boldsymbol{x}_{\boldsymbol{i}}$ and $\boldsymbol{y}_{\boldsymbol{i}}$, and, are the total average of the predicted and actual data.

$$
\varepsilon(n)=M S E=\frac{\sum_{i=1}^{n}\left(y_{p i}-y_{t i}\right)^{2}}{n}
$$



Oilfields

Initially, the information about the excavation of the formation was collected from the daily excavation reports of Khangiran field and entered into Excel. The factors influencing drilling penetration rates (ROPs) included in these statements are: drilling area $(\mathrm{m})$, drill type, drill size (inches), drilling depth (m), drill operation time (h), weight On the drill (WOB), drill rotational speed (RPM), flower weight (MW), pump injection rate (Q) (gallons per minute), and pump strain pressure (P) (PAM). These parameters were considered as input and drill penetration rate (ROP) as theoutput of CSA-LSSVM model. The ordered data were divided into two groups of training (80\%) and a test (20\%) using a random permutation. These data were also normalized to 0 to 1 before entering the machine learning process.

\section{CONCLUSION}

In this study, the primary objective is to determine the relationship between mechanical parameters, hydraulic parameters and environmental parameters to predict and achieve the highest rate of drilling. Toachieve the objective of operational data in Iran, this research is based on the capabilities of a support machine to provide a model for predicting drilling speed with different parameters. Not to mention the model that has been introduced, depending on the laboratory or operational conditions, only some of the factors affecting the drilling rate are used in the model. The results show that it is possible to obtain a reasonable and reliable relationship between these parameters using the least squares method. Based on the results of the CSA-LSSVM model in this study, the total correlation coefficient between the total drill penetration rate recorded in the drilling reports and its predicted value is 989. And the absolute error of the mean also shows a low value of 839. This very strong overlap between data predicted by machine learning algorithms and laboratory data can be attributed to the very strong relationship between the input and output parameters that came from the daily drilling reports. According to the obtained results, the model made in this study can be used with a high degree of confidence in prediction of drill penetration rate in Khangiran field Formations. Moreover, in this research, by interfering the following factors, a model for forecasting the rate of bit penetration in various rock formations and structures will be presented.

\section{REFERENCES}

[1] Saidi,A., 1987. Reservoir engineering of fractured reservoirs, Volume I

[2] Saidi,A., 1987. Reservoir engineering of fractured reservoirs, Volume II.

[3] Morten, J. drilling in thesalt formation and rate of penetration modeling,petroleumgeo science and engineering. ,June 2014

[4] Al-Betairi, E. A., Moussa M.,and Al-Otaibi. Multiple Regression Approach to Optimize Drilling Operationsin the Arabian Gulf Area. SPEJ,83-88. , March 2005

[5] Bourgoyne, A. T. Millheim, K. K.,Chenevert M. E. and Young, F. S., Applied Drilling Engineering, ninth edition, SPE, Richardson, Vol. 2, p. 232. 2003

[6] Bourgoyne, A. T. \&Young, F. S.,"A Multiple Regression Approach to optimal Drilling and Abnormal Pressure Detection",SPEJournal, PP. 371-384, Aug. 1974

[7] Sadorsky, P Modeling and forecasting petroleum futures volatility, Energy Economics 28, 467-488. 2006

[8] Morris, David. J. 1987. Special Drilling Operations. Petroleum Extension Services, Austin, Texas.

[9] Burgoyne, D. J. and Young T. C,1984. Applying a genetic Neuro-model Reference Adaptive Controller in Drilling Optimization. World Oil Magazine, 228: 29-38.

[10] Bourgoyne, A. T. \&Young, F. S.,"A Multiple Regression Approach to optimal Drilling and Abnormal Pressure Detection",SPEJournal, PP. 371-384, Aug. 1974

[11] Sadorsky, P Modeling and forecasting petroleum futures volatility, Energy Economics 28, 467-488. 2006

[12] Barragan, R. V. and Santos, O. L. A,1997. Optimization of Multiple Bit Run. Presented at the SPE/IADC Drilling Conference, the Netherland, Amsterdam, SPE 37644, 4-6.

[13] Bahari, M. H. Bahari,M. negativeMoharram, F. And NaghibiSistani, M. B. June. 2008, determining Bourgoyne and young model coefficients using ageneticalgorithm to predict drilling rate. Journal of Applied Sciences 8, Volume17.

[14] Morris, David. J. 1987. Special Drilling Operations. Petroleum Extension Services, Austin, Texas.

[15] Warren, T. M., "Penetration- Rate Performance of Rolle-Cone Bits",SPE Drilling Engineering, PP. 9-18, March 1978

[16] Cunningham R. A., "An Empirical Approach for Relating Drilling Parameters", JPT, PP. 987-991, July. 1978 
[17] Bourgoyne, A. T. \&Young, F. S.,"A Multiple Regression Approach to optimal Drilling and Abnormal Pressure Detection",SPEJournal, PP. 371-384, Aug. 1974

[18] Corrie R. D., “An analytical solution to estimate optimum number of development wells to achieve maximum economical returns," SPE 7143,Presented at the SPE Annual Technical Conference and Exhibition Held in New Orleans, Louisiana, 30 Sept. 3 Oct. 2001

[19] Kahraman, S. "Rotary and Percussion Drilling Rate Prediction Using Regression analysis", International Journal of Rock Mechanics and Mining Science 36 PP. 981-989, 1999

[20] Bahari, M. H,Bahari, A. nejatimoharrami, F. And NaghibiSistani, M. B., determining Bourgoyne and young model coefficients using ageneticalgorithm to predict drilling rate. Journal of Applied Sciences 8, Volume17: 3050-3054. June. 2008

[21] Han, J.,Kamber, M., Data Mining: Concepts and Techniques (2 ed. ), Morgan Kaufmann, 2006

[22] Witten, I., Frank, E., Data Mining: Practical Machine Learning Tools and Techniques (2 ed.), Morgan Kaufmann Pub, 2005.

[23] Olson, D.,Delen, D., Advanced Data Mining Techniques, Springer Verlag, 2008.

[24] Zhang, J., Shi, Y., Zhang, P., "Several Multi-Criteria Programming Methods for Classification," Computers \& Operations Research, Vol. 36, No. 3, 2009, pp. 823-836.

[25] Fisher, R., "The use of Multiple Measurements in Taxonomic Problems," Annals of Eugenics, Vol. 7, No. 2, 1936, pp. 179-188.

[26] Vapnik, V., Lerner, A., "Pattern Recognition using Generalized Portrait Method," Automation and Remote Control, Vol. 24, No. 6, 1963, pp. 774-780.

[27] Mangasarian, O., "Linear and Nonlinear Separation of Patterns by Linear Programming," Operations Research, Vol. 13, No. 3, 1965, pp. 444-452.

[28] Freed, N., Glover, F., “A Linear Programming Approach to the Discriminant Problem,” Decision Sciences, Vol. 12, No. 1, 1981, pp. 68-79.

[29] Boser, B.,Guyon, I.,Vapnik, V., “A Training Algorithm for Optimal Margin Classifiers,” Presented at Annual Conference on Learning Theory (COLT), New York, USA, 1992.

[30] Cortes, C., Vapnik, V., “Support-Vector Networks,” Machine Learning, Vol. 20, No. 3, 1995, pp. $273-297$.

[31] Osuna, E., Freund, R.,Girosi, F., “Support Vector Machines: Training and Applications,” Massachusetts Institute of Technology, 1997.

[32] Mangasarian, O. , "Generalized Support Vector Machines", Advances in Neural Information Processing Systems, Vol. 10, 1999, pp. 135-146.

[33] Suykens, J. ,Vandewalle, J. , "Least Squares Support Vector Machine Classifiers", Neural processing letters, Vol. 9, No. 3, 1999, pp. 293-300.

[34] Schölkopf, B., et al. , "New Support Vector Algorithms", Neural Computation, Vol. 12, No. 5, 20009 pp. 1207-1245.

[35] Lee, Y. ,Mangasarian, O. , “RSVM: Reduced Support Vector Machines”, Presented at SIAM International Conference on Data Mining, Chicago, USA, 2001.

[36] Lee, Y. J. ,Mangasarian, O. L. , "SSVM: A Smooth Support Vector Machine for Classification", Computational Optimization and Applications, Vol. 20, No. 1, 2001, pp. 5-22.

[37] Mangasarian, O. ,Musicant, D. , "Lagrangian Support Vector Machine”, Journal of Machine Learning Research, Vol. 1, 2001, pp. 161-177.

[38] Mangasarian, O. ,Musicant, D. , “Active Support Vector Machine Classification”, Advances in Neural Information Processing Systems, Vol. 13, 2001, pp. 577-583.

[39] Mangasarian, O. , Wild, E. , "Proximal Support Vector Machine Classifiers", Presented at International Conference on Knowledge Discovery \& Data Mining (KDD), San Francisco, USA, 2001.

[40] Shi, Y. , et al. , "Data Mining in Credit Card Portfolio Management: a Multiple Criteria Decision MakingApproach", Presented at International Conference on Multiple Criteria Decision Making (MCDM), Ankara, Turkey, 2001.

[41] Bugera, V. , Konno, H. , Uryasev, S. , “Credit Cards Scoring with Quadratic Utility Functions”, Journal of Multi-Criteria Decision Analysis, Vol. 11, No. 4-5, 2002, pp. 197-211.

[42] Peng, Y., Shi, Y., Xu, W., "Classification for Three- Group of Credit Cardholders' Behavior Via a Multiple Criteria Approach”, Advanced Modeling and Optimization, Vol. 4, 2002, pp. 39-56.

[43] Hsu, C. , Chang, C. , Lin, C. , “A Practical Guide to Support Vector Classification 9”'Department of Computer Science, National Taiwan University, Taipei 106, Taiwan, 2003. [56] Bi, J., "Multi-Objective Programming in SVMs", Presented at International Conference on Machine Learning (ICML), Washington DC, USA, 2003. 
[44] Perez-Cruz, F., et al., "Extension of the nu-SVM Range for Classification”, Nato Science Series Sub Series, Computer And Systems Sciences, Vol. 190, 2003, pp. 179-196.

[45] Asada, T., et al. , "Pattern Classification by Goal Programming and Support Vector Machines 9" Computational Management Science, Vol. 1, No. 3, 2004, pp. 211-230.

[46] Shi, Y., et al., "Classifying Credit Card Accounts for Business Intelligence and Decision Making: A Multiple-Criteria Quadratic Programming Approach", International Journal of Information Technology \& Decision Making (IJITDM), Vol. 4, No. 04, 2005, pp. 581-599.

[47] Kou, G. , et al. , “A New Multi-Criteria Convex Quadratic Programming model for Credit Analysis", Presented at International Conference on Computational Science (ICCS), Reading, UK, 2006.

[48] Zhang, J., Shi, Y., “A Framework of Optimization Method for Classification”, Presented at International Symposium on Optimization and Systems Biology (OSB), Beijing, China, 2007.

[49] Kou, G. , et al. , "Multiple Criteria Mathematical Programming for Multi-Class Classification and Application in Network Intrusion Detection”, Information Sciences, Vol. 179, No. 4, 2009, pp. 371 - 381.

[50] Ben-Hur, A. , Weston, J. , “A User's Guide to Support Vector Machines”, Methods in Molecular Biology, Vol. 609, 2010, pp. 223-239.

[51] Zhang, D., Tian, Y., Shi, Y., "A Group of Knowledge-Incorporated Multiple Criteria Linear Programming Classifiers", Journal of Computational and Applied Mathematics, In Press, 2011.

[52] V. Vapnik, The nature of statistical learning theory, Springer-Verlag, New York, 1995.

[53] J. A. K. Suykens, J. Vandewalle, Least Squares Support Vector Machine Classifiers, Neural Processing Letters, 9 (1999) 293-300.

[54] K. Pelckmans, J. A. K. Suykens, T. V. Gestel, J. D. Brabanter, L. Lukas, B. Hamers, B. D. Moor, J. Vandewalle, LS-SVMlab: a MATLAB/C toolbox for Least Squares Support Vector Machines, Leuven, Belgium, 2002.

[55] N. Metropolis, A. W. Rosenbluth, M. N. Rosenbluth, A. H. Teller, E. Teller, Equation of State Calculations by Fast Computing Machines, The Journal of Chemical Physics, 21 (1953) 1087-1092.

[56] S. Xavier-de-Souza, J. A. K. Suykens, J. Vandewalle, D. Bolle, Coupled Simulated Annealing, Systems, Man, and Cybernetics, Part B: Cybernetics, IEEE Transactions on, 40 (2010) 320-335.

[57] L. Hamel. Knowledge Discovery with Support Vector Machines, Hoboken, N.J. John Wiley, 2009.

[58] K. Maji. Weight Optimization of MLP using Swarm Intelligence and Genetic Algorithms. Department of Computer Science \& Engineering, Faculty of Engineering and Technology, Jadavpur University Kolkata 700032 INDIA Master of Computer Application, Submission Year: 2010.

\section{AUTHORS' BIOGRAPHY}

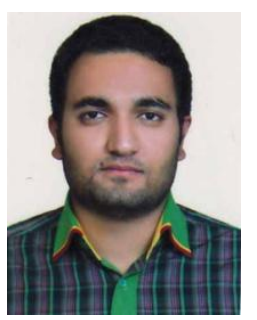

Masoud Kakoli, Master degree of Petroleum Engineering at Islamic Azad University, Tehran science and research Branch. My current interests in petroleum engineering sciences include, Drilling engineering, laboratory experimental investigations and analytical tests. Furthermore, he concentrated more on the utilization of SVM Approach and suggested optimum solutions to Predict the Performance of Drilling Operation.

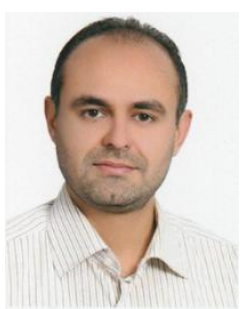

Dr. Arash Ebrahimabadi, is associate professor and M.SC. and doctoral student supervisor, and head of Department of Mining Engineering at Islamic Azad University, Qaemshahr Branch, Iran, where he specializes in interaction of mechanical miners and rock mass, engineering rock mechanics, mechanized tunneling and underground mining, rock cutting, petroleum Geomechanics and drilling. He cooperates (as part time) with Department of Petroleum Engineering, and Department of Mining Engineering at Azad University, Science and Research Branch, Tehran South Branch and Central Tehran Branch, Tehran, Iran. He managed several research projects for the office of vice chancellor for research and technology of Islamic Azad University, Qaemshahr Branch. He has served as mine supervisor and technical advisor in drilling operations for seven years. To date, Dr. Ebrahimabadi has published more than 70 papers and one book entitled "Roadheader's performance evaluation". He is a referee and member of scientific committee for Journal of Environmental Geology as well as head of scientific committee for Mine Sciences Conference (Iran). He is a member of Iranian Mining Engineering Organization (IMEO), Iranian Society of Mining Engineering (IRSME) and Iranian Society for Rock Mechanics (IRSRM). 
A Model to Predict the Performance of Drilling Operation Using SVM Approach in One of the Iranian Oilfields

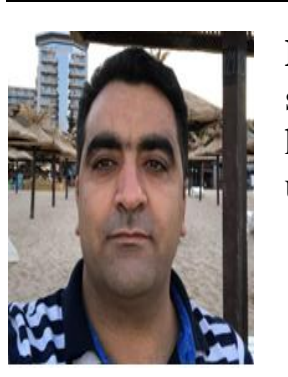

Dr. Behnam Mirshekari, is associate professor and M.SC. and doctoral student supervisor at Islamic Azad University, Tehran science and research Branch, where he specializes in Drilling engineering and operates such related projects in the university.

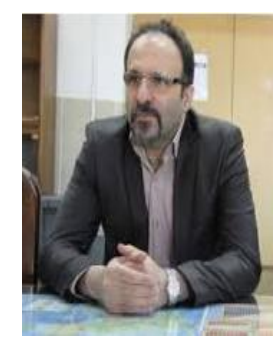

Dr. Jamal Sheikhzakariaee, is associate professor and M.SC. and doctoral student supervisor, and Deputy of Petroleum and Chemical Engineering Campus at Islamic Azad University, Tehran science and research Branch, where he specializes in geological engineering and operates such related projects in the university.

Citation: Masoud Kakoli, et.al (2018). A Model to Predict the Performance of Drilling Operation Using SVM Approach in One of the Iranian Oilfields, International Journal of Petroleum and Petrochemical Engineering (IJPPE), 4(2), pp.9-16, DOI: http://dx.doi.org/10.20431/2454-7980.0402002

Copyright: () 2018 Masoud Kakoli, (2018). This is an open-access article distributed under the terms of the Creative Commons Attribution License, which permits unrestricted use, distribution, and reproduction in any medium, provided the original author and source are credited 